\title{
GIRA EL MON I TORNA AL BORN
}

\author{
Joaquim Casal i Bataller \\ (Universitat Autònoma de Barcelona)
}

L'any 1961 l'editorial Seix i Bartal va publicar un plec d'articles del professor J. L. Atanguren sota l'epígraf La juventud europea y otros ensayos; d'aquests articles el més conegut ha estat precisament el dedicat a la joventut, que ja havia estat publicat feia poc en la «Revista de la Universidad de Madrid». La manca d'escrits sobre el tema i, sobtetot, el tarannà acadèmic i polític de l'autor varen influir decisivament en la difusió i el coneixement de l'article arreu del pais, bàsicament -és clar-entre la població universitàtia. Malgrat que la refiexió fou feta sobre les tendències de la joventut en el període 1945-1960, durant la dècada dels seixanta l'article es convertí en veritable llibre de text per a molts, i fins i tot es va emprar per analitzar els fets de Maig del 68 . El refux del moviment estudiantil en la primera part dels setanta va obrir un període de silenci o de tesituació que no s'ha trencat fins que els efectes socials de la crisi econòmica han incidit de ple en el món juvenil, alterant les coordenades educació-ocupació.

De fa uns cinc anys cap aquí el món dels joves, particularment el pas de l'escola a la vida activa, obre de nou un amplíssim camp de recerca i experimentació. Què passa quan la promesa de «plena ocupació» deixa de ser promesa? Heus aquí la qüestió. De nou s'emprèn el tema de la joventut com a problema, però tanmateix amb unes coordenades històriques i socials diferents.

Entre el text que escrigué el professor Aranguten i la situació actual hi ha un quart de segie de distància. ¿Quines tesis de les mantingudes 
aleshores avui encara mantenen una vigència $i$ continuen aportant, amb les corresponents matisacions, elements per a interpretar la situació actual? Aquest ha estat el sentit de la meva relectura de l'article.

És cert que hi ha alguns aspectes que evidentment han quedat caducs, ja que l'assaig es circumscriu a la realitat dels anys cinquanta. És cert també que moltes posicions allí mantingudes estan inspirades en un marc humanístico-cristià que no és el de tots. Però en la relectura de l'article hi he redescobert fins una dotzena de qüestions que avui dia encara tenen rabiosa actualitat, on l'autor aporta elements encara vigents per a la comprensió d'aspectes de la realitat juvenil.

\section{Joventut, generació i nupcialitat}

Enguany encara és obert el tema de l'acotament demogràfic de la població juvenil: quines són les fronteres de la joventut quant a edats? D'altra banda s'apunta un tema parallel que avui pren encara més importància: l'allargament del període juvenil a causa dels problemes d'inserció laboral i accés a l'habitatge: "Me siento un poco encorsetado cuando intento guiarme por la pauta rectilinea de esas generaciones matemáticamente determinables $i$ determinadas... Sin embargo parece necesario acotar una edad. Necesidad tanto más sentida aquí, en España, donde estamos asistiendo boy al extraño espectáculo de una anormal prolongación de la etapa juvenil: el becho de que la independencia económica suficiente para contraer matrimonio o establecerse $y$ vivir por cuenta propia suele llegar, por desgracia, tarde parece autorizar el uso de seguir considerando "jóvenes" a bombres de 30,35 o más años... Nosotros nos inclinaríamos a tomar como edades-limite los 15 y los 30 años, con lo que es respetado el período generacional de quince años de duración.»

\section{L'«esdeveniment generacional» com a marca}

Hi ha un esdeveniment generacional que dibuixa la matriu de la problemàtica juvenil. Als anys vuitanta l'esdeveniment radica en la crisi del model de creixement econòmic $i$ social de la societat dita postindustrial. L'atur de primera ocupació ha deixat de ser un problema quantitatiu (nombre de joves parats) per esdevenir un problema qualitatiu (afectació en el camp dels valors i les actituds del conjunt de la població juvenil). Per al professor Aranguren l'esdeveniment generacional de la joventut dels anys cinquanta és el plec de conseqüències derivades de la Guerra Mundial (i la 
Guerra Civil en el nostre cas). Canviant el mot «guerra» per «atur» el text recobra actualitat: «El acontecimiento generacional que ba definido a la actual juventud ba sido, sin duda alguna, la guerra última... La experiencia que tiene de la guerra la generación joven es la de haber nacido en ella o de ella. El acontecimiento pesa como un fatum exterior, impenetrable, incomprensible... Lo impuesto a esta generación es ese "becho bruto" que pesa sobre ella, como un destino que, no queriéndolo y sin entenderlo siquiera, es "suyo" sin baber tenido ninguna parte en él.»

\section{Decepció $i$ passotisme com a actituds}

L'esdeveniment generacional (guerra per un costat i crisi del model de desenvolupament econòmic i social per l'altre) genera la proliferació d'un sentiment de decepció $\mathrm{i}$ una actitud de desenteniment de les coses públiques (llegiu passotisme): «Haber nacido de la guerra o en la guerra es también baber nacido a la decepción... Porque se tenia que poner de relieve el abrupto desnivel entre unos ideales retóricamente proclamados... y la realidad ocultada tras ellos y al final descubierta... La generación anterior a la que consideramos fue predominantemente política. Con su retórica política desencadenó la guerra... y una profunda decepción. Lo impuesto a la nueva generación, en su realidad bruta, es insoslayable... y la actitud fundamental de la generación actual ba consistido en recusarlo. Recusarlo no entrando en polémica con ello, sino, simplemente, desentendiéndose de ello... Lo depuesto es, por tanto, aquel falaz idealismo... Lo característico de la actual juventud es el desplome de los ideales, la desilusión y, consecuentemente, en mayor o menor grado, el escepticismo... Lo puesto por esta generación es el atenimiento positivo a la realidad... en la acomodación funcional a la realidad inmediata.»

\section{La privacitat com a tendència}

La concreció, en el camp de la pràctica, de la desconfiança i la decepció condueix a l'exaltació del quotidià, a la no-articulació del present a plans a mitjà o llarg termini, en definitiva a l'exaltació del «privat» com a esfera del «segur» o del «sentit», i a l'absència de proposta. «Una generación que descontia de los ideales y aun de todo principio, programa o proyecto, en realidad no puede "pro-poner" nada: se limita a poner ese atenimiento a la realidad sin más pretensión que la de vivir al día... Se trata de una generación sin epónimos, sin maestros reconocidos... Lo que si ocurre, como 
reaccion de desconfianza respecto de los grandes ideales politicos, ideales que condujeron al desastre, es una privatización de la existencia. El joven de boy tiende a asegurarse una sólida situación profesional y una satisfactoria vida familiar, a refugiarse en su vida privada."

\section{El conformisme social}

La dècada del seixanta en general i els esdeveniments del seixanta.vuit en particular van ser una punta en l'anomenada «revolta» juvenil. D'aleshores ençà la tendència ha canviat de sentit i direcció donant 'pas a la generalització de conductes marcades per un conformisme i per una acceptació «no-plausible» de la realitat donada: «El individualismo existencial de quien se propone, por encima de todo, preservar y mejorar el reducto de su vida privada y cotidiana exige, como contrapartida, un conformismo social fácilmente observable en la juventud europea de boy... El gobierno del mundo, piensan la mayor parte de los jóvenes, depende de fuerzas oscuras y supraindividuales sobre las que ellos no tienen ninguna posibilidad de influir... La generación actual no es ya, en ese sentido, una generación politica. Tampoco es que haya regresado al viejo apoliticismo. Se ba despolitizado en cuanto que, sumamente escéptica por lo que se refiere a las "ideologías" y los mitos politicos, no está dispuesta a dejar que lo público invada el ámbito de su existencia privada. La nueva generación no es "revolucionaria" en el sentido de antes de la guerra, pero tampoco "conservadora". Su interés, de acuetdo con la actitud ante la vida... se dirige, sobre todo, a la elevación del nivel de vida y a la eficacia funcional... La gente en general y los jóvenes en particular aspiran a vivir tranquilos. Los partidos conservadores de Europa son los favorecidos por este escepticismo politico y esta primacía de la vida privada.»

\section{L'associacionisme poltitic}

Un altre tret que avui marca el «ser jove» és la seva baixa vinculació a organitzacions polítiques; aquest tret ha merescut més rellevància encara en el nostre país, atès el període de transició política del setanta-cinc al vuitanta. No es pot negar que des de les institucions polítiques i els grups polítics aquest fet és viscut amb preocupació, i no és poca la tinta gastada per a patlar del passotisme polític i dels baixos nivells d'associacionisme polític o sindical. Heus aquí el que diu el professor Aranguren dels joves dels anys cinquanta: «La juventud actual ba traído un cambio de actitud. 
Escéptica como en todo en cuanto a las virtudes misticas de la Gemeinschaft que pretendia abrazar la vida entera de la persona, cuando se asocia lo bace o de modo no organizado, bajo la forma de simple grupo de amigos, o de modo funcional, para fines muy concretos, y nunca como tal juventud (a no ser. que se trate de la defensa de intereses estrictamente juveniles, como es el caso de los sindicatos o asociaciones universitarias). Así por ejemplo, han desaparecido las anteriores "Juventudes" de los partidos politicos y los sindicatos europeos están boy probablemente menos politizados que antes.»

\section{L'allargament de l'estada a la llar paterna}

Durant la dècada dels seixanta un dels temes centrals en el debat entorn de la joventut gira sobre la família. La institució familiar es converteix en una de les dianes predilectes de l'anomenada «contracultura». Per aquest camí s'obre pas el moviment de «comunes» com a via alternativa. Parallelament a les comunes s'accelera el procés de separació o independència familiar en no pocs joves (separació que comunament no es dóna fins a la nupcialitat). Aquesta sortida avançada de la família precisament es va convertir en un dels eixos de preocupació dels pares, talment que la tendència semblava convertir-se en dominant. Anys després, petò, els escrits sobre el tema prenen tanmateix una orientació diferent: s'enfoca la qüestió de l'allargament de l'edat juvenil, de l'allargament del periode de permanència a la llar paterna, de l'«adolescència forçada», de la suavització del conflicte generacional, etc. Doncs bé, obviant les raons econòmiques que intervenen de forma desigual entre un període i l'altre, el professor Aranguren diu: «No bay más bogar que el familiar. Esta obvia constatación ha aumentado la vinculacion familiar. No es que el joven de boy espere encontrar en sus padres lo que no pueden ser, sus camaradas, ni menos que esté dispuesto a volver a la sumisión filial de las antiguas generaciones; pero el buen sentido por su parte, y la juvenilización creciente de los padres, con una mejor disposición para la comprensión, facilitan boy las relaciones familiares,»

\section{Noves maneres d'entendre el treball}

Es indubtable que entre la conjuntura dels cinquanta $i$ la dels vuitanta hi ha una distància molt llarga. Després de la guerra mundial es prefiguren les bases del que serà el model de desenvolupament accelerat al voltant 
del qual es reforcen les teories de Ia mobilitat social i del paper decisiu de l'ensenyament en els processos de creixement social i promoció individual. Tanmateix és cert que als anys vuitanta tots aquests pressupòsits han fet figa $i$ que el mercat de treball presenta alteracions estructurals indub. tables. D'aquí que es comença a escriure sobre les noves actituds i els nous valors dels joves davant del treball. Fa vint-i-cinc anys Aranguren va escriure: «La relación del joven europeo con su trabajo se ba establecido bajo el signo de la inseguridad. Por eso lo que principalmente busca este joven en el trabajo es el logro de una situación estable, que proporcione seguridad $y$ perspectivas de elevacion social. El trabajo no es considerado ya como el sentido total de la existencia, ni su relación con él es concebida como fundamentalmente moral y aun religiosa, sino de una manera realista, positiva, como puro medio, al que sin embargo se pide que aporte algo espiritualmente valioso, que sea "interesante". Los jóvenes europeos de boy ponen el "interés" del trabajo en que permita desarrollar la propia inicia. tiva, en que no sea rutinario y en su mayoria prefieren el trabajo "técnico"."

\section{Universitat i ocupació}

Si la literatura de fa uns anys abundava sobre la necessitat de titulats de grau mitjà i superior, sobre la necessària expansió de les taxes d'escolarització universitària i sobre la Universitat com a via de promoció, fa uns cinc o vuit anys que els escrits apunten cap a l'atur dels llicenciats, cap al procés de subocupació dels titulats, cap a la pèrdua del valor de canvi de l'educació, i fins i tot s'ha arribat a titllar la Universitat de efàbrica d'aturats». Salvant les distàncies en el temps i en el pes de l'afirmació, es deia: «Los jóvenes llegan a la Universidad inmaduros a causa de una for. mación pasiva en el colegio... y sin tiempo apenas para aprehender el espiritu universitario, se ven abrumados en seguida por la preocupación de las "salidas" profesionales, en algunos paises - por ejemplo Españatan oscuras e inciertas, y la amenaza de caer dentro del cada día más numeroso "proletariado intelectual"."

\section{Imatge $i$ so contra lletra impresa}

També és cert que l'actual imperi de la imatge i el so sobre la lletra impresa ha fet escriure no poca gent. Fins $i$ tot pet a alguns el segle xx, amb la pantalla, tanca el llarg període de la impremta. També salvant les distàncies, es diu que «Por otra parte el cine desplaza a las formas propia. 
mente literarias, de la misma manera que la vida juvenil es inimaginable boy sin la música de disco. Los jóvenes de boy, en contraste con lo que ba ocurrido a los de otras generaciones, no sienten especial predilección por las formas literarias o artísticas de vanguardia, como no sea en los casos en que este disconformismo puede servir como expresión simbólica de otro disconformismo más funcional, el politico-social».

\section{Separació de la «cosa pública»}

Un dels altres aspectes que sol aparèixer en el decàleg de qüestions referents a la joventut actual és el seut distanciament en relació a la vida pública, a la dimensió collectiva de les coses, atès el fenomen de la fragmentació social. "Los jóvenes actuales son reservados, descontiados y aun escépticos. Propenden a desentenderse de la vida pública porque, como ya jimos, no creen poder influir realmente sobre ella. Pero su refugio en la vida privada - familiar y profesional, sin idealismos- sería injusto calificarlo de "evasión"... La mayoría de los jóvenes franceses -y, con toda probabilidad, de cualquier otra nación también- aceptan plenamente su época y su país, pese a todos los defectos que ciertamente encuentran en ellos.»

\section{Inconformisme $i$ grups radicals}

La major part de la literatura sobre joventut sempre deixa un racó, per petit que sigui, per dir quatte paraules sobre l'aparició, el sentit i la desaparició de grups minoritaris que capitalitzen les formes de contestació radical. Qui no ha llegit res sobre els punk, funky, afterpunk, bavy, etc.? Fa vint-icinc anys es deien d'una altra manera. «El escepticismo de los jóvenes de nuestro tiempo se manifiesta, mayoritariamente, bajo formas de adaptación $e$ integración social, $y$, por tanto, de conformismo, por superficial que éste sea. Sin embargo, la juventud actual quedaria insuficientemente caracterizada si omitiésemos aludir a sus reacciones minoritarias, violentamente inconformistas, aunque siempre en forma de lo que podríamos llamar la "rebelión inútil"... En la mayor parte de los paises democráticos se está a punto de alcanzar el "tecbo" de las reivindicaciones y mejoras posibles dentro del sistema $e$, igualmente, se produce esa vivencia de que las cosas no pueden ya "dar más de sí" y sobreviene el aburrimiento. La energía no utilizada y ni siquiera encauzable estalla entonces tumultuosamente: son los teddy boys ingleses, son por una parte los tricheurs y por otra los blou- 
sons noirs franceses, son los Halbstarke alemanes, son los leppisti vitelloni italianos... y son los "gamberros" celtibéricos de nuestro país... La acción por la acción, aunque sea bárbara o criminal, permite la evasión de un mundo absurdo y condenado, tal vez, a una inmediata destrucción. Esta evasión es buscada por otros a través de la entrega al éxtasis rítmico de la música moderna, a través de una "vida literaria" excéntrica, como en el caso de los angry men ingleses o de la Beat Generation americana.»

Encapçalava aquesta selecció de cites de l'assaig del professor Aranguren amb una vella dita barcelonina - tot canvia perquè tes no canvii,, totes les coses retornen al punt d'origen, etc.-, tanmateix poc apropiada en referir-se a dos períodes històrics pez als quals no tenim en compte interpretacions cícliques de la història a l'estil de Toymbee. Quedi, doncs, ben clar que, en presentar el vell assaig en referència a qü̈estions que avui s'estan plantejant entorn de la joventut, la meva intenció no és pas dir que el moment actual pot parangonar-se amb la joventut dels cinquanta; diria més: les distàncies són abismals. En la telectura del text, però, hom observa com s'apunten $i$ es perfilen unes qüestions que avui dia encara són objecte de recerca i debat.

És per això que en cap cas no voldria fer referència o judici sobre els aspectes del plantejament que han quedat antiquats en el canvi de conjuntura econòmica i social; més aviat crec que la rememoració d'aquest escrit, carregada de tints malenconiosos per a molts de nosaltres, contribueix a donar dimensió històrica a la qüestió juvenil plantejada en la dècada dels vuitanta. 